\section{Cystic fibrosis, the key link with airborne alpha emitting nanoparticulates}

\author{
Florent Pirot*
}

Independent Researcher, Valbonne, France

\section{Abstract \\ Cystic fibrosis is explained in this paper that suggests tackling the disease by elimination of the most significant sources of contamination.}

\section{Introduction}

For nonpathological human beings, the contamination with alpha-emitting nanoparticulates (an IARC Class 1 carcinogenic) in the upper respiratory tract is progressively incorporated through the gastrointestinal tract, through the lymphatic system or by dissolution and absorption into the blood [1], channels that allow ulterior elimination (after the yielding of some damage through the patterns of interaction of radioactivity with human cells) through miction, defecation and ejaculation, especially when there is no $\mathrm{Cl}$ - accumulated in the brain and nervous system [2] and no meat consumption as meat "digestion" converts the alpha-emitting nanoparticulates into breakers of the otherwise impossible-to-digest layers of fat and flesh, where they tend to remain incrustated, cycling back into the bloodstream through bowels instead of fecal excretion and reaching much more secluded parts of the body [3]. But this pattern does not apply to children with cystic fibrosis, due to their congenital anomaly that makes them pure accumulators of this contamination.

\section{Pathogenesis}

The toxicity of the mucus and the progressive nature of cystic fibrosis are explained by the attraction created for alpha-emitting nanoparticulates (from radon in buildings, from "NORMs" in water, phosphated fertilizers, oil, coal ore, natural gas etc. and their circulation in the food chain (esp. accumulation in meats) \& waste incineration fumes, and from nuclear accidents, depleted uranium weapons...) by $\mathrm{Cl}-$ accumulation in the lungs and digestive tract as chloride is not properly evacuated due to the CFTR dysfunction.

The mechanism is then identical as what is described in [2] for neurological disorders. The progressive increase of alpha

\author{
More Information \\ *Address for Correspondence: Florent Pirot, \\ Independent Researcher, Valbonne, France, \\ Email: florent.pirot@orange.fr \\ Submitted: June 10, 2021 \\ Approved: June 17, 2021 \\ Published: June 18, 2021 \\ How to cite this article: Pirot F. Cystic fibrosis, \\ the key link with airborne alpha emitting \\ nanoparticulates. J Pulmonol Respir Res. 2021; \\ 5: 049-050. \\ DOI: 10.29328/journal.jprr.1001023 \\ ORCiD: orcid.org/0000-0003-0823-615X \\ Copyright: @ 2021 Pirot F. This is an open \\ access article distributed under the Creative \\ Commons Attribution License, which permits \\ unrestricted use, distribution, and reproduction \\ in any medium, provided the original work is \\ properly cited. \\ Keywords: Pathogenesis; Health physics; \\ Alpha emitting nanoparticulates; Uranium; \\ Thorium; Radon; Radium; Polonium; Plutonium; \\ Oncogenesis; Nanoparticulates; Particulate \\ matter; Aerosolized particulates \\ A) Check for updates \\ OPen access
}

decay in nanoparticulates due to the typically shorter and shorter half lives as decay advances (except for atoms heavier than uranium) explains the progressive nature of CF. This progressive acceleration is typical of all diseases related with alpha-emitting nanoparticulates - other articles of the author, relying on a large review of the existing literature and on own findings, give a series of examples $[4,5]$ (concluding with celiac disease, where the phenomenon is also quite similar) [6].

It is possible to explain for instance why a patient was found positive to multiple sweat chloride tests without CF symptoms [7], the one-month old baby obviously had of course no serious exposure to alpha-emitting nanoparticulates yet.

For patients with normal sweat chloride tests and CF signs, one explanation is simply that the negativity in the mucus has been balanced by enough alpha-emitting nanoparticulates leaving no excess $\mathrm{Cl}$ - for the test; even though other configurations may also explain such results, for instance particular mutations where sweat does not reveal the $\mathrm{Cl}$ accumulation [8] and falsification of CF signs by e.g. attentionseeking parents (compare with [9]).

Wherever alpha-emitting nanoparticulates accumulate, their decays lead to tumorogenesis through bystander effect (proximity effect) in cells damaged but not destroyed [10] and 
the quoted literature in the above listed publications of the author. The high prevalence of e.g. gastrointestinal cancers in CF patients [11] is hence easily explained.

\section{The "hot particle" debate}

The 1976 EPA notice attempted to open the debate on the issue of whether particle size matters vs. more uniform radiation distribution. In the case of children with cystic fibrosis, due to the size of the mucus area, a more uniform distribution is slightly more dangerous than the same level of alpha activity concentrated in a single "hot particle", because of the nature of cancer and because of the opportunities for removal. The thin radium dust from diesel motors for instance is likely to cause, everywhere the levels of intermediate damage that are ideal for uncontrolled cell proliferation i.e. tumorogenesis, whereas a single very hot particle is likely to directly cause necrosis (in a way akin to what is attempted in alphatherapy against cancer, where necrosis of tumorous cells is seeked). And the very hot particle could be removed somehow more easily because the alpha charges can be used for pull effect by getting the children in front of a cup of black or green tea ${ }^{1}$ and renewing the cup frequently (the cup should not be drank by the child, it is to stimulate excretion through upper ways and spitting) - the cups, held close to the mouth but far from the chest (the head should advance to reach the cup, the mouth and the cup should be level, the chest farther away from the cup than the mouth), could also be combined with series of shut-down but pluggedin electricity-powered machines not far from the mouth of the child, so the excedentary electrons come out and also help (as the child's chest is farther away than his/her mouth from the machines full of electrons, the electrons will help). A kind of foam should get out of the mouth, this foam, from Bose-Einstein condensation has to be eliminated in a sink (see also [3]). Much more time will be needed to remove a large amount of lowly-radioactive nanoparticles. However, the hot particle requires immediate care or it is likely to disaggregate (because of decays inside of it) and scatter, then becoming more and more nefarious. Which is why pathogenesis is, on average, more a function of the amount of radioactivity in the lungs than of its distribution, as argued already in [1].

${ }^{1}$ Coffee still works in intakes in the general case because it is still less acidic than alpha-emitting nanoparticulates (when made with water filtrated from NORMs) and its contribution to cardiovascular activity helps in a different way the elimination but for cystic fibrosis subjects spitting in green tea cups will be the most efficient cleanser.

\section{Other suggestions for better care}

The maximal reduction of the contamination by alphaemitting nanoparticulates offers the safest prospects for the future of patients. There remains a natural soil contamination that, even with entirely alpha-emitting free human industries (in the most general sense of "industries") cannot be avoided and children with $\mathrm{CF}$ will naturally suffer more from these, the elimination of the genetic deficit by using e.g. CRISPR-CAS9 technology could help for bridging the gap.

\section{References}

1. Health Effects of Alpha-Emitting Particles in the Respiratory Tract: Report of Ad Hoc Committee on "Hot Particles" of the Advisory Committee on the Biological Effects of lonizing Radiations, United States Environmental Protection Agency, 1976.

2. Pirot $F$. The link between salt and neurological disorders: the mediation of alpha emitting nanoparticulates as simple explanation. Porto Biomed J. 2019; 4: e55.

PubMed: https://pubmed.ncbi.nlm.nih.gov/33501397/

3. Pirot F. Spitting as traditional medicine - why alpha-emitting nanoparticulates make spitting an unfortunate but significant contribution to health. Int J Traditio Complemen Med. 2021; 6: 33.

4. Pirot F. Traumatic Brain Injury: a Case Report and Its Contribution to Understanding the Underlying Mechanisms - Alpha-Emitting Nanoparticulates Proven as Key. Am J Med Case Rep. 2020; 8; 100-102.

5. Pirot F. Physics of Moses' Exodus, of vampire myths, of family structures, of modern ideologies, and of the celiac disease. Eur J Appl Sci. 2021; 9: 162-173.

6. Pirot F. Cases of sexual diseases with alpha-emitting nanoparticulates: Parkinson's, Primary Biliary Cholangitis (prostate and clitoris) - and opening the breast implant debate. Int Res J Public Health. 2021; 5: 49.

7. Cotten SW, Bender LM, Willis MS. Multiple Positive Sweat Chloride Tests in an Infant Asymptomatic for Cystic Fibrosis, Laborat Med. 2012; 43: 2.

8. Silva Filho LVF, Carvalho Feirreira Bussamra MH, Aversa Nakaie CM, Villac Adde F, Rodrigues JC, et al. Cystic fibrosis with normal sweat chloride concentration - case report. Rev Hosp Clin Fac Med Sao Paulo. 2003; 58: 260-262.

PubMed: https://pubmed.ncbi.nlm.nih.gov/14666323/

9. Leonard A, Leal T, Godding V, Villanueva P, Wallemacq P, et al. Sweat potassium concentration may help to identify falsification of sweat test: a case report. Clin Biochem. 2008; 41: 1110-1112. PubMed: https://pubmed.ncbi.nlm.nih.gov/18554505/

10. Belyakov OV, Malcolmson AM, Folkard M, Prise KM, Michael BD. Direct evidence for a bystander effect of ionizing radiation in primary human fibroblasts. Bri J Cancer. 2001; 84: 674-679. PubMed: https://pubmed.ncbi.nlm.nih.gov/11237389/

11. Yamada A, Komaki Y, Komaki F, Micic D, Zullow S, et al. Risk of gastrointestinal cancers in patients with cystic fibrosis: a systematic review and meta-analysis. Lancet Oncol. 2018; 19: 758-767. PubMed: https://pubmed.ncbi.nlm.nih.gov/29706374/ 